\title{
Qualitative Adjectives in EFL Students' Reflective Writing Essays
}

\author{
Tanju Deveci, Nader Ayish \\ Khalifa University \\ Correspondence concerning this article should be addressed to Tanju Deveci, English Department, \\ Khalifa University, Al Saada St - Zone 1 - Abu Dhabi, UAE. E-mail: tanjudeveci@yahoo.com
}

\begin{abstract}
Qualitative adjectives are often used in expressive writing, including reflective writing. They express and (de)intensify feelings and emotions, thereby expressing stance. This study investigates the adjective profiles of 60 first-year EFL students' reflective essays and compares male and female university students' utilization of qualitative adjectives and those used as attitudinal stance markers. Data were collected from a reflective writing task after students participated in a seminar on effective listening. Analyses were conducted considering the General Service List (GSL), the Academic Word List (AWL), and words that do not appear in either of the preceding lists. The results indicated that qualitative adjectives accounted for $6 \%$ of the words in these reflective writing essays, and the male students used a greater number of adjectives than the female students. This difference, which was at a statistically significant level, likely stems from male students' greater use of adjectives from the Academic Word Lists. The results also showed that $47.5 \%$ of the adjectives used in these essays were attitudinal. There was no statistically significant difference between the frequencies with which the male and the female students used these attitudinal adjectives. The results are discussed and recommendations are made to increase students' effective use of adjectives in reflective writing.
\end{abstract}

Keywords: adjectives, attitudinal markers, freshman students, gender, qualitative adjectives, reflective writing

\section{Introduction}

Adjectives are used to describe the qualities or attributes of nouns. In this way, they point to the distinctions made between nouns. Such is the place of adjectives in language that a sentence without adjectives provides information, but it does not say much (Murray, 2014). Adjectives are also used to express attitude and stance. As such, they are utilized quite frequently in expressive writing, which encourages individuals to use verbal expressions on their thoughts and feelings about lived experiences (Beaumont, 2018). Expressive writing comes in many forms, one of which is reflective writing. In addition to certain core skills such as description, critical analysis, self-awareness, and evaluation, reflective writing requires clear and concise articulation of thought processes, which necessitates the use of good written English (Handler, Handler, \& Gill, 2011).

Although various aspects of effective language use in reflective writing have been noted (e.g., organization, syntax, sentence length, appropriate lexis, and personal language), adjectives-a key component of expressive writing-have received inadequate attention. This is despite a few studies that have highlighted the essential role adjectives play in expressive writing (Adams, 2013; Lee, Fitria, \& Ginting, 2019). While reflective thinking and writing are taught and practiced in different disciplines of higher education, especially in professional degree programs such as teacher education (Hagevik, Aydeniz, \& Glennon, 2012; Hatton \& Smith, 1995; Moon, 2006; Zulfikar \& Mujiburrahman, 2018) medical and health professional education (Bernard, et al., 2012; Crowe \& O’Malley, 2006; Nguyen, Fernandez, Karsenti, \& Charlin, 2014; Schön, 1987) and engineering (Kilgore, Sattler, \& Turns, 2013; Reidsema, 2009; Turns, Newstetter, Allen, \& Mistree, 1997; Wallin \& Adawi, 2018), little research has examined how students use language to write reflectively (Hatton \& Smith, 1995; Russell, 2005). One reason for this lack of research is due to the nature of reflective writing. Students, for example, often perceive reflective writing as an unfamiliar genre and ancillary to their core studies. Questions as to how to teach and assess reflective writing simply add to the challenge of conducting such research (Dyment \& O’Connell, 2011; Kember et al., 2008; Plack, et al., 2005; Sumsion \& Fleet, 1996). 
Unless trained well, using language effectively can be a formidable challenge for students, especially those pursuing education in a foreign language. The lack of research in this area is what led us to want to better understand how our students write reflectively. This is particularly true relative to the use of adjectives, because so little is known about the linguistic patterns of how students use adjectives to express themselves in reflective writing. So too can examining how females and males use adjectives in reflective writing. In this paper, therefore, we describe our Emirati freshman students' reflective writing behavior at the end of a seminar within the context of an undergraduate English and Communication course.

\section{Theoretical Background}

\section{Adjectives}

An adjective is

a word used with a noun to denote some quality, attribute, or fact, which we connect in thought with that for which the noun stands, without making as distinct assertion that the quality or attribute belongs to what we are speaking about (Mason, 1858, p. 13).

Mason (1858, pp. 32-36) identified three types of adjectives:

a) qualitative adjectives denoting some quality or attribute;

b) quantitative adjectives denoting how much or how many of a particular thing we have in our thoughts. These include the indefinite article, the cardinal numeral adjectives, words such as all, few, more, most, both, etc., and;

c) demonstrative/determinative adjectives pointing out which thing(s) we are speaking of out of the class of things denoted by a common noun. These include the definite article, the adjective pronouns, pronominal adjectives, and the ordinal numbers.

Another classification is made in Collins Cobuild English Grammar (as cited in Stillar, 1988), according to which there are five major categories: a) qualitative, b) emphasizing, c) classifying, d) color, and e) postdeterminers. We chose the first two of these five types of adjectives based on the aims of our study. In addition, they are the ones one would expect to see more often in reflective essays (Çapar, 2014; Ferris, 2009). Qualitative and emphasizing adjectives, for example, express feelings, attitudes, and stance and serve as building blocks of expressive and reflective writing. Postdeterminers, on the other hand, are outside the scope of our study because they function as grammatical structures rather than lexical items. Classifying adjectives are also outside the study's scope because they serve as attributive adjectives and classify their associated nouns. As for color adjectives, while they function to simply describe the color of something, we paid special attention to any use of color adjectives used to denote feelings and attitudes.

The majority of adjectives are comprised of qualitative adjectives. This is one reason why instructional materials targeting learners of English tend to focus on qualitative adjectives in their explanation of what an adjective is. This appears to be the case for lower-level learners in particular. The other two types of adjectives, 'quantifiers' or demonstratives, are often treated as distinct grammatical structures with little, if any, mention of their attributes as adjectives. Many learners of English, as well as native speakers, are likely unfamiliar with the classification of such grammatical structures as adjectives. This study, therefore, only focuses on qualitative adjectives in order to account for this unfamiliarity. Among the various meanings qualitative adjectives have is the one of position/attitude, as in the examples 'a key point' and 'the beautiful message' (Stillar, 1988). Such examples highlight the attributes qualitative adjectives assign to things, people, concepts, etc. from some point of view. From this perspective, they play a key role in expressive language, which is under the scope of the current research.

\section{Reflective Thinking and Reflective Writing}

Reflective thinking allows individuals an opportunity to internalize and reconstruct newfound knowledge and make sense of lived experiences (Boud, Keogh, \& Walker, 1985; Burns \& Bulman, 2000; Mezirow, 1998; Ryan, 2011). While definitions of reflective thinking vary, a common theme among many is that thinking reflectively is essential for one's personal growth and development (Lew \& Schmidt, 2011; Rodgers, 2002). According to Boyd and Fales (1983), for example, reflection is the "Process of internally examining and exploring an issue of concern, triggered by an experience, which creates and clarifies meaning in terms of self and which results in a 
changed conceptual perspective" (p. 99). This definition best captures our understanding of reflective thinking as it applies to our research context.

Reflective writing stems from reflective thinking and it is often used as a pedagogical strategy to clarify thinking and to give more time and space for deeper and more meaningful reflection about something of significance (Tsingos-Lucas et. al, 2017; Nunn \& Brandt, 2016). In this sense, reflective writing reinforces learning by encouraging students to thoughtfully think through key concepts and ideas related to a course. Rusche and Jason (2011) reiterate this by saying reflection in the form of writing engages students in an examination of their own writing which results in their learning to "value the process of learning, inquiry, and critical self-reflection while acquiring and constructing self-knowledge” (p. 1). Reflective writing has also been shown to help students contextualize the new information they are learning, refrain from meaningless memorization of factual information, and "see learning as a never-ending journey that does not stop outside of the classroom or after they have graduated” (Cisero, 2006, p. 231).

Moon (2004) notes that reflective writing is the external expression of the mental process of reflection though such expression is unlikely to be the same as what takes place in one's head. The cycle in which reflection takes place is comprised of three stages, which have come to be known as the reflective cycle (Deveci \& Nunn, 2018). The first stage includes the description of an experience in relation to what happened in context as well as the writer's feelings aroused by the experience. The second phase includes the writer's evaluation and analysis of the experience. The final stage includes the writer's reflection on what he/she has learned from the experience and how he/she plans to improve future experience. Considering the fact that reflective writing allows the writer to explain his/her rationale and thought processes to others (Brown, 2016), it engages the writer in interpersonal communication. This is supported by Gibbs' observation (as cited in Rodgers, 2002, p. 845) that "reflection needs to happen in community, in interaction with others." This points to the role writing as a linguistic skill plays in effective communication, which is described in detail in the following section.

\section{Language Use in Reflective Writing}

Reflective writing often shares a number of features with traditional essay writing. Examples include a wellorganized structure, the correct use of tenses, and lexical variety. Reflective writing may also require students to make references to relevant content from lectures so that their instructor can gain insight into their thinking and learning processes as well as how they interpret the information they have been presented. Reflective writing also adds the elements of personal experience, first person, and present and future tense (Eckstein \& Ferris, 2018; MacLellan, 2004). The language used in reflective writing, therefore, tends to be mostly personal and subjective. One reason for this is because reflective writing tasks are often personal in nature (e.g., "Reflect on an experience you recently had with your team"). While students are expected to write in the first person and incorporate concrete and abstract language into their reflections, many find this type of genre writing challenging and uncomfortable compared to more familiar and traditional academic writing tasks (Burton \& King, 2004; King, 2001; Lyubormirsky, Sousa, \& Dickerhoof, 2006). Part of the reason for this stems from the experience some students have had with academic essays that tells them that the use of the personal pronoun "I" should be avoided. Another reason is because students may worry about how such tasks are going to be assessed (Wong et al., 1995).

Tone is another complicating factor students must contend with when writing reflectively. Although tone is dependent on the topic and purpose of a particular style of writing, reflective writing, unlike traditional academic essays (which tend to be serious and formal) may be ironic and informal or something in between. This flexibility in tone adds to the challenge of writing reflectively (Ferris, 2009; Lu \& Ai, 2015). So too does the use of 'show, don't tell' as an effective writing strategy where the student is expected to use sensory details to illustrate something (e.g., "He was sweating profusely as he stood on stage before the large audience") rather than simply state something directly (e.g., "He was very nervous on stage"). These reflective writing characteristics, in particular, encourage the use of adjectives to bring writing to life.

Writing in general and reflective writing in particular appear to be more challenging for those who write in English as a foreign language (EFL), which is the context in which the current study was conducted. These writers have to put more cognitive effort into their writing (van Weijen, 2014), find it more difficult to write due to factors like limited lexis, syntax, and organization (Al Murshidi, 2014; Englander, 2014; Handler et al., 2011), and suffer from a lack of stylistic competence (Buckingham, 2008). In fact, Deveci (2015) and Deveci (2017) 
found that Emirati freshman students' vocabulary usage in reflective writing essays was heavily based on the list of the first 2000 most common words only (i.e., General Service List (West, 1953)), which may not be adequate for a writer to fully express themselves. Along with these difficulties, students' inability to think critically (Thabet, 2008), think reflectively (Ayish, 2020), and write reflectively prior to coming to university creates additional problems, all of which require tailor-made support (Moussa-Inaty, 2015).

\section{The Use of Adjectives in Reflective Writing}

According to OxbridgeEssays (n.d., parag. 22) ${ }^{1}$, reflective writers should utilize adjectives to describe their experiences. Therefore, it is best to tap into a "wide range of adjectives" and use specific rather than "vague adjectives such as 'okay' or 'nice' to express oneself." For example, "My little brother wants to be a bigshot lawyer when he grows up." Writing in this way helps the reader better visualize what is being described. Similarly, Jefferys (2018) points to the importance of using concrete and abstract forms of language in reflective essays. He notes that the former, in particular, helps the writer bring life to his/her writing and draw the reader into an essay through the use of sensory or descriptive details. Using adjectives with concrete language enhances the impact of the description (e.g., "her high voice" and "a metallic smell"). "This reflection of the details in the essay is part of what brings the author's voice to the reader. The point of this type of essay is to bring that reader as close to the experience as possible," argues Jefferys (2018, parag. 4). Birney (2012, p. 203) also found that strong writers of reflective essays used adjectives judiciously when they "were 'appraising" or reasoning in writing "about a particular topic." Other research, too, revealed that the use of feeling and thinking verbs with adjectives (e.g., "a positive impact") and reasoning adverbs with adjectives (e.g. "extremely challenging") was among the linguistic features strong reflective writers were able to utilize (Gibson et al., 2017).

It is also important to note expressions of stance (i.e., the expression of personal feelings, attitudes, value judgements, or assessments (Biber et al., 1999)) in reflective essays. These expressions are at the heart of a writer's ability to express feelings, emotions, and lived experiences (Beaumont, 2018). Among the various grammatical devices writers can use to express stance are adjectives, which can appear in adjectival predicates (e.g. " "To me, it's just amazing that ...”) or the writer's lexical choice (e.g. “They are very nice, cats are.”). Such use of adjectives, then, can be labelled as an attitudinal stance marker in that an adjective "can reasonably be interpreted as either a positive or negative attribute to a proposition" since they can be, for example, "'good' or 'bad', 'important' or 'unimportant', 'certain' or 'uncertain"' (Forsell, 2011, p. 27). According to the Scottish Examination Board (1992 as cited in Klenowski, 2002), writers ought to express a clear and appropriate stance in reflective essays. Similarly, Hardy and Friginal (2016) note that expressions of stance are used to express stance in other types of university-level writing including creative writing and response papers.

Despite the important role adjectives play in reflective essays, to our knowledge, there is no research conducted to identify the actual adjective coverage in a well-written effective reflective essay. However, we analyzed the sample essay we provide our students with when teaching reflective writing skills. We found that the adjective coverage of the essay was $8 \%^{2}$. We also analyzed the adjective coverage of reflective essays written by five highachieving students in our previous classes. The average coverage of adjectives in their essays was $7.5 \%$. We therefore concluded that a successful reflective essay should have adjective coverage of approximately $8 \%$.

\section{Language Use and Gender Differences}

The personal and contextual nature of reflective writing makes it difficult to compare and quantify differences between the genders (Magno, 2009). Nonetheless, some research has shed light on the use of language by males and females in general and on adjectives in particular. The findings appear to be inconsistent. For example, research by Alkhrisheh, Aziez, and Alkhrisheh (2019) showed that male and female university students used language in a similar fashion. Likewise, Rubin and Greene (1992) found that male and female university students' writing is far more similar than different. On the other hand, other research revealed that female students, in comparison to their male counterparts, had a greater tendency to use adjectives indicating personal feelings (Ishikawa, 2015) and attitudes (Barczewksa \& Andreasen, 2018; Wenjing, 2012).

\footnotetext{
${ }^{1}$ Oxbridge Essays (2020, January 20). A complete guide to reflective essay. https://www.oxbridgeessays.com/blog/complete-guide-to-writinga-reflective-essay/

${ }^{2}$ The sample essay had been written by the course coordinator a few years before the current study took place. Several course instructors had also given feedback on it.
} 
According to Lakoff (1975, p. 51), some adjectives are gender neutral and may be used by males or females (e.g., great, terrific, cool, and neat), but other adjectives are mostly used by females (e.g., adorable, charming, sweet, lovely, and divine). For example, both males and females may say, "What a terrific idea," but only females are likely to say, "What a divine idea" (Lakoff, 1975, p. 52). Ishikawa (2015, p. 597), on the other hand found that male students tended to use "adjectives and verbs related to social economic activities (social, democratic, lose, eat, appear, avoid)" more often than female students. While Lakoff (1975) highlighted linguistic differences between males and females, it is not very clear if it is gender that drives language use (Baker, 2014; Eckert,1989; Newman, Groom, Handelman, \& Pennebaker, 2008; Tannen, 1990), factors such as the age of the speaker, listener, or social status of the interlocutors (Coates, 2016; Ishikawa, 2011), or a combination of elements. Taken together, previous literature on the use of adjectives points to the need to better understand how males and females perceive and use language (and especially adjectives) to communicate and write reflectively.

\section{Research Questions and Hypotheses}

In this research, we describe the performance of the students without instructional intervention. Towards this end, we sought answers to the following questions:

1 a) What is the adjective profile in the students' reflective essays?

b) Is there a difference between the adjective profiles in the female and male students' reflective essays?

a) What adjectives are used as attitudinal stance markers in the students' reflective essays?

b) Is there a difference between the female and male students' use of these adjectives?

Based on these questions and the relevant literature reported above, we formulated the following hypotheses:

1. Approximately $8 \%$ of the students' reflective essays will be comprised of qualitative adjectives.

2. A greater number of the qualitative adjectives in the student essays will be based on the General Service List (GSL).

3. An important number of the qualitative adjectives will be attitudinal markers.

4. The female and male students will use qualitative adjectives with similar frequencies.

5. The female students will use attitudinal adjectives more often than their male counterparts.

\section{Materials and Methods}

\section{Participants}

Sixty Emirati first-year students (30 male and 30 female) in a freshman communication course at an Abu Dhabibased university participated in the study. Their ages ranged between 18 and 21, with a mean age of 19. Most students (87\%) attended government schools where Arabic is the medium of instruction and where English is taught as a foreign language starting in grade 1. While students are required to have IELTS scores of 6 overall to enter our university, they do not necessarily have a 6 in writing.

\section{Data Collection Tool}

Data were collected using a reflective writing task assigned at the end of a seminar on effective listening, which was the first of a set of seminars on a variety of communication-related topics including interpersonal communication, intrapersonal communication, and intercultural communication. The task required the students to respond to the following prompt:

Which of the poor listening practices do you think is the most harmful and why? Describe a situation in which you experienced this practice. Analyze and evaluate this experience in relation to the concepts presented in the readings, and state how you would modify any of your future listening behaviors to become a better listener.

While the content of the seminar text has a particular focus on poor listening practices, it also includes the characteristics of effective listeners and effective listening practices. During the seminar itself, ample classroom discussions were held on students' effective and ineffective listening experiences. Therefore, by the time 
students were asked to respond to the prompt, their awareness had already been raised significantly. This assignment was chosen because reflective writing is an important aspect of the current course as well as other courses students take as part of their program of study. Identifying students' behaviors of reflective writing (without instructional intervention) could also serve as a diagnostic tool and help inform course instruction. Teaching ideas generated from this assignment are included in the conclusion of the paper.

While the students were not taught anything about adjectives, because the study aimed to describe their writing behavior at the beginning of the communication course, the rubric shared with the students included a general component of language use in addition to other aspects of writing such as content, organization, and task completion. The language component, which weighed less than the other components, included three main aspects:

a) style and expression: developed and engaging, with a consistent level of formality appropriate to the task.

b) grammar and vocabulary: sophisticated and appropriate use of a broad repertoire

c) clarity and accuracy: evidence of thorough, careful proofreading, correct spelling and punctuation.

Prior to completing the task, students were given instruction as to why reflective writing within the context of their academic studies is important. In addition, they received details about the reflective cycle as defined by Deveci and Nunn (2018). They also received instruction on different ways of organizing reflective essays, how to develop content that is supported by the relevant literature, and the need to include their personal experiences. They were asked to address their responses to their instructors, and they were reminded about the previously mentioned rubric that would be used to evaluate their writing.

\section{Analysis}

Of the three types of adjectives identified by Mason (1858), this study focused on qualitative adjectives. Therefore, only the qualitative adjectives in the student reflective essays were analyzed. Adjective profiles were examined based on the General Service List (GSL) (West, 1953), which is composed of the 2000 most common words only, the Academic Word List (AWL) (Coxhead, 2000), which contains 570 word families that appear frequently in academic texts, and the Off-list, which are words that do not appear in any of the preceding lists. In doing this, free online software was used (http://www4.caes.hku.hk/vocabulary/profile.htm).

Through a norming session, we (the two researchers) separately identified the adjectives in the students' reflective writing papers. The interrater agreement reached was $90 \%$. We then compared the results, discussing the relatively low number of differences, until we reached an agreement. We followed a similar pattern in identifying the adjectives used as an attitudinal stance marker in the students' reflective writing. A third independent researcher was involved at this stage. We excluded the items on which we could not agree.

Descriptive statistics such as frequencies and percentages were used to describe the data sets. In comparing the data sets according to gender, log-likelihood (LL) similarity was used. Following Rayson, Berridge, and Francis (2004), a LL value of 3.84 or higher was considered significant at the level of $p<0.05$.

\section{Results}

The first research question aimed to describe the adjective profile of the student reflective writing essays and asked whether the female and the male students' adjective profiles differed from each other. Results are presented in Table 1.

\section{Table 1}

Adjective profile of reflective writing essays

\begin{tabular}{ccccccccccc}
\hline \multicolumn{3}{c}{ All } & \multicolumn{1}{c}{ Male } & \multicolumn{5}{c}{ Female } \\
\hline Word count & Adj count & \% of adj & Word count & Adj count & \% of adj & Word count & Adj count & \% of adj & LL & p \\
\hline 20,588 & 1,234 & 6 & 8,310 & 593 & 7.1 & 12,278 & 641 & 5.2 & +29.84 & 0.000 \\
\hline
\end{tabular}


According to Table $1,6 \%$ of the student essays were made up of adjectives. Table 1 also shows that the male students had a greater tendency to use adjectives than the female students (7.1\% vs. $5.2 \%$ ). The computed value of log-likelihood (LL) was 29.84>3.84, which indicates a significant difference between the two data sets at a statistically significant level $(\mathrm{p}=0.000)$.

The adjectives in the texts were also analyzed according to word lists. Results are summarized in Table 2.

Table 2

Adjective profiles according to word lists

\begin{tabular}{lcccccccc}
\hline & \multicolumn{2}{c}{ All } & \multicolumn{2}{c}{ Male } & \multicolumn{3}{c}{ Female } \\
\hline & $\#$ & \% & $\#$ & \% & $\#$ & \% & LL & p \\
\hline GSL & 798 & 64.7 & 360 & 60.7 & 438 & 68.3 & -2.77 & 0.078 \\
AWL & 269 & 21.8 & 157 & 26.5 & 112 & 17.5 & +11.47 & 0.002 \\
Off-list & 167 & 13.5 & 76 & 12.8 & 91 & 14.2 & -0.43 & 0.000 \\
Total & 1,234 & 100 & 593 & 100 & 641 & 100 & & \\
\hline
\end{tabular}

As can be seen in Table 2, students had a greater tendency towards the use of adjectives from the GSL (64.7\%). This was followed by the AWL (21.8\%) and the Off-list (13.5\%). It is also shown that the two groups of students generally had a similar tendency towards using adjectives despite the slight differences between percentages. The only significant difference between the data sets was in regards to the AWL words; the male students tended to use a greater number of adjectives in this category than did the female students (26.5\% vs. $17.5 \%)$. The LL value was $+11.47>3.84$ with a $p$ value of 0.002 , which indicates a statistically significant difference.

The second research question aimed to identify the adjectives used as an attitudinal stance marker in the students' reflective essays and whether or not the male and female students' usage of them differed. Data related to this question are summarized in Table 3 below.

Table 3

Attitudinal adjectives in relation to total number of adjectives

\begin{tabular}{cccccccccc}
\hline & All & \multicolumn{3}{c}{ M } & \multicolumn{4}{c}{$\mathbf{F}$} \\
\hline$\#$ & \% of total adjectives & $\#$ & \% & \# of total adjectives & $\#$ & \% & \# of total adjectives & LL & p \\
\hline 586 & 47.5 & 258 & 43.5 & 593 & 328 & 51.2 & 641 & -3.82 & 0.052 \\
\hline
\end{tabular}

According to Table 3, the total number of attitudinal adjectives used by the students was 586, which accounts for $47.5 \%$ of the total number of adjectives $(1,234)$. The table also shows that the female students tended to use a greater number of attitudinal adjectives than the male students $(51.2 \% \mathrm{vs}, 43.5 \%)$ in relation to the total number of adjectives in each set of reflective writing essays (593 and 641 respectively). However, the computed LL value of -3.82 was slightly below the benchmark of 3.84, indicating a lack of statistical difference.

We also looked at the frequency with which each attitudinal adjective was used and compared these according to gender. The results can be seen in Table 4 .

As shown in the table, the top ten most frequently used adjectives included important, effective, bad, harmful, good, better, efficient, poor, negative, and hard. And only two categories of adjectives compiled according to frequencies revealed differences at statistically significant levels, and these were to the advantage of the female students. One of the categories was good, which occurred 33 times (10\%) in the female data set, but only 8 times in the male data set. The other category included those with single occurrence. Of the 72 adjectives in this category, a significant number (52) were present in the female data set. Examples included thoughtful, bitter, careless, irritated, wonderful, perfect, problematic, key, minor, and mindful. For this category, the log-likelihood value was 5.49>3.84. On the other hand, the adjectives positive and big were each used twice by the female students, but ten times by the male students $(\mathrm{LL}=+7.91>3.84)$. Similarly, the adjective efficient was used only by the male students. 
Table 4

Attitudinal adjectives according to gender

\begin{tabular}{|c|c|c|c|c|c|c|c|}
\hline \multirow[t]{2}{*}{$\#^{3}$} & \multirow[t]{2}{*}{ Adjectives } & \multicolumn{2}{|c|}{ Male } & \multicolumn{2}{|c|}{ Female } & \multirow[t]{2}{*}{ LL } & \multirow[t]{2}{*}{$\mathbf{p}$} \\
\hline & & $\#$ & $\%$ & $\#$ & $\%$ & & \\
\hline 69 & important & 29 & 11.2 & 40 & 12.2 & -0.11 & 0.738 \\
\hline 65 & effective & 32 & 12.4 & 33 & 10 & +0.71 & 0.4 \\
\hline 58 & bad & 27 & 10.5 & 31 & 9.5 & +0.15 & 0.699 \\
\hline 46 & harmful & 20 & 7.8 & 26 & 7.9 & -0.01 & 0.94 \\
\hline 41 & good & 8 & 3.1 & 33 & 10 & -10.95 & 0.001 \\
\hline 20 & better & 8 & 3.1 & 12 & 3.7 & -0.13 & 0.716 \\
\hline 16 & efficient & 16 & 6.2 & - & - & - & - \\
\hline 14 & poor & 6 & 2.3 & 8 & 2.4 & -0.01 & 0.93 \\
\hline 13 & negative & 7 & 2.7 & 6 & 1.8 & +0.5 & 0.478 \\
\hline 11 & hard & 8 & 3.1 & 3 & 0.9 & +3.72 & 0.054 \\
\hline 9 & wrong, easy, difficult & 9 & 3.5 & 18 & 5.5 & -1.29 & 0.000 \\
\hline 8 & successful & 2 & 0.8 & 6 & 1.8 & -1.25 & 0.001 \\
\hline 7 & huge & 4 & 1.6 & 3 & 0.9 & +0.48 & 0.000 \\
\hline 6 & positive, big & 10 & 3.9 & 2 & 0.6 & +7.91 & 0.008 \\
\hline 5 & right, essential & 7 & 2.8 & 3 & 0.9 & +2.75 & 0.003 \\
\hline 4 & helpful, serious, mad, main, complex & 6 & 2.3 & 14 & 4.8 & -1.66 & 0.001 \\
\hline 3 & $\begin{array}{l}\text { mindless, easier, boring, relevant, embarrassing, strong, significant, necessary, } \\
\text { uncomfortable, angry, fundamental }\end{array}$ & 17 & 6.6 & 16 & 4.9 & +0.74 & 0.000 \\
\hline 2 & $\begin{array}{l}\text { sad, critical, painful, annoyed, comfortable, worse, fake, great, worst, } \\
\text { disorganized, excellent, sufficient, basic, dangerous, harder, small, bored, } \\
\text { simple, best, possible, ignorant, frustrated }\end{array}$ & 20 & 7.8 & 24 & 7.3 & +0.04 & 0.000 \\
\hline \multirow[t]{2}{*}{1} & $\begin{array}{l}\text { thoughtful, bitter, careless, false, useful, rare, irritated, responsible, distracting, } \\
\text { earnest, hostile, irrelevant, careful, wonderful, respectful, perfect, weak, } \\
\text { monotone, disoriented, competent, disappointed, excited, ethical, valuable, } \\
\text { problematic, new, preconceived, suitable, addictive, active, fine, stimulating, } \\
\text { mean, high, acceptable, disrespectful, distorted, suffocating, key, innocent, } \\
\text { nonjudgmental, meaningful, unable, amazing, worried, informative, attentive, } \\
\text { special, tiny, tough, dominant, stressed, annoying, average, central, smart, } \\
\text { shocked, old, judgmental, normal, happy, outstanding, attracting, minor, } \\
\text { appropriate, interesting, total, energetic, mindful, beneficial, misunderstood, } \\
\text { enormous }\end{array}$ & 22 & 8.5 & 50 & 15.2 & -5.49 & 0.002 \\
\hline & Total & 258 & 44 & 328 & 56 & & \\
\hline
\end{tabular}

\section{Discussion}

One of the aims of the current research was to describe the adjective profile of the students' reflective writing essays. Results showed that $6 \%$ of the student essays were comprised of adjectives. This result negates our first hypothesis stating approximately $8 \%$ of the students' reflective essays would be comprised of qualitative adjectives. The ratio of adjectives detected in the study is considered limited based on the arguments made in the literature that the personal nature of reflective writing often requires the writer to make references to feelings (Ullmann, 2019), which necessitates their utilization of adjectives in addition to other language elements. Effective reflective writers have also been noted to use "a wide range of adjectives" (OxbrigeEssays, n.d.) including concrete and abstract forms to help bring life to writing and engage the reader through the use of sensory and descriptive details (Jefferys, 2018). These observations, coupled with findings from past research indicating that adjectives in reflective essays frequently occur with nouns and adverbs, point to the relatively common use of adjectives in the genre investigated in this study. Still, the lack of previous research focusing on

\footnotetext{
${ }^{3}$ Delineates each word separately
} 
corpus analysis of reflective essays prevents us from fully supporting our expectation with greater empirical data. Nevertheless, we consider the relevant literature and the preliminary data reported in the current study to be a modest contribution to the field.

Challenges students face in writing reflective essays, including language use, have been noted in other contexts, too. Students taught to describe events without deeply engaging their own thought processes, for example, encounter formidable obstacles when asked to reflect on these events from a personal stance (Mann, Gordon, \& MacLeod, 2007). The same is true for students who have taken countless standardized tests requiring them to regurgitate factual information, which has an impact on their skills in "asking questions, problem-solving, and learning to think new ways" (Mauk \& Metz, 2013, p. 448). Similarly, Thabet (2008) found that public schools in the UAE fell short of fostering critical thinking as a main objective for education and that teachers often opted for memorization as the main teaching strategy. It is likely that such an approach impacts students' reflection skills in general and reflective writing skills in particular.

From the perspective of language use, Handler et al. (2011) observed that many students-especially nonnative speakers of English-face significant difficulties in using written English correctly, and exhibit poor grammar, spelling, punctuation, and sentence and paragraph cohesion. As non-native English speakers with little to no previous exposure to reflective writing, the students in our study likely experienced similar challenges. This is supported by recent research revealing that many Emirati students that attended high schools where Arabic is the medium of instruction encountered difficulty transitioning to a university where English is the medium instruction (EMI) (Ayish, 2020). Other research also showed that Emirati students at an EMI university had difficulty writing reflectively and required language support as well as guidance for reflection (Moussa-Inaty, 2015).

Evidence for students' somewhat limited skills in using adjectives in reflective writing essays may also be found in their greater dependency on the GSL. Results from the current study showed that the majority of adjectives (64.7\%) in student essays belonged to the GSL, which confirmed our second hypothesis (i.e., "A greater number of the adjectives in the student essays will be based on GSL"). A more sophisticated and advanced level of language use could have encouraged students to tap into a wider variety of lexis from the AWL. A closer look at how student grades are determined also showed that language use is weighted less than the other components of the rubric used to assess the essays (i.e., content, organization, and task completion). In addition, it is worth noting that the language component focused on students' skills in using a broad repertoire of engaging, sophisticated, and appropriate vocabulary together with other aspects of grammatical and mechanical aspects of writing. Emirati first-year university students' reliance on the GSL in reflective writing essays was revealed in our previous research conducted at the same institution (Deveci, 2015). A similar study we conducted also showed that first-year students' self-rating of their ability to use the AWL words was low (Deveci, 2017). These two studies, in fact, helped us formulate the second hypothesis. Other research found that vocabulary was another challenging aspect of writing for Emirati international students (Al Murshidi, 2014). Although the focus of these past studies was not on adjectives per se, the findings point to the attention required for students' development of lexical dexterity within an academic environment.

The current research also sought to identify the adjectives used as an attitudinal stance marker. Of the 1,234 adjectives in the student reflective essays, a significant number (586), accounting for $47.5 \%$, were attitudinal adjectives. Given the nature of the task, this was an expected result, which confirmed our third hypothesis that an important number of the adjectives in the student essays would be attitudinal markers. Attitudinal stance markers are indeed an important characteristic of reflective writing, and adjectives play a key role in expressing feelings, emotions, thoughts, and lived experiences (Beaumont, 2018). Other similar types of university-level writing such as response papers and creative writing have also been shown to include more language used to express stance and mental processes (Hardy \& Friginal, 2016). In other contexts, stance is also considered a significant factor in determining the success of reflective writing. For instance, the Scottish Examination Board (1992 as cited in Klenowski, 2002) stipulate that successful reflective writing clearly shows the writer's distinctive voice through the use of a clear and appropriate stance. The writer is also required to make his/her writing vivid and original, exploiting the possibilities of language resourcefully and subtly. The significant proportion of the attitudinal adjectives utilized by the students in the current study can be considered a natural attempt to adhere to these requirements. 
We also compared the students' adjective use according to gender. The data revealed that adjectives, in general, were used more by the male students than the female students, which was confirmed by statistical results ( $L L=+29.84>3.84$ ), which negates our fourth hypothesis (i.e., "The female and male students will use qualitative adjectives with similar frequencies"). This also contradicts the findings of previous research by Alkhrisheh, Aziez, and Alkhrisheh (2019) who found no significant differences between male and female university students' use of language. Our finding also differs from earlier research findings indicating that the writing of male and female university students is far more similar than different (Rubin \& Greene, 1992).

As per the students' use of attitudinal adjectives, however, the female students used them with higher frequencies than the male students $(51.2 \%$ vs. $43.5 \%)$, confirming our fifth hypothesis despite the lack of statistically significant levels of differences in general, except for the adjective good, which was used extensively by the female students compared to the male students ( $L L=10.95>3.84)$. Ishikawa (2015) also found that female students had a greater tendency to use adjectives denoting personal feelings (e.g., disgusting) in their academic essays. Similarly, Wenjing (2012) found that strong attitudinal adjectives such as precious, adorable, and charming were used more often by women than by men. In their study of adjectives, Barczewska and Andreasen (2018), too, found that women tended to use more of the eight adjectives (i.e., good, bad, big, small, ugly, pretty, different, important), which could be categorized as attitudinal markers. Theirs was an academic spoken discourse, but the finding on the higher frequency of attitudinal adjectives by women concurs with our finding. Taken together, these findings support Newman et al.'s (2008) observation that women are more likely to use words that express personal attitude than men. These findings also contradict earlier observations that women's and men's use of language is more similar than different (Alkhrisheh et al., 2019; Rubin \& Greene, 1992), at least from the perspective of adjective use.

We also observed that the female students' use of attitudinal adjectives was more varied, with a significant number of adjectives being used only once. This may have been a factor in encouraging the female students' use of a greater number of attitudinal adjectives. This result may also support Lakoff's (1975) observation that males and females often use different adjectives. Still though, the results of the current study do not seem to provide strong evidence for differences between male and female language use. We suspect that the nature of reflective writing made it difficult for us to compare and quantify differences between genders, as was previously suggested by Magno (2009).

\section{Pedagogical Implications}

The findings from this research point to important pedagogical implications. First, they offer insight into how students in our English courses, without direct instruction, incorporate the use of adjectives while writing reflectively. The results showed that qualitative adjectives accounted for only $6 \%$ of the students' reflective writing essays. As we noted earlier, an absence of adjectives provides information, but not much else (Murray, 2014). Indeed, the infrequent utilization of these lexical items in reflective writing can limit learners' effective expression of reasoning, emotions, and attitudes. Thus, for foreign language learners studying in an EMI institution, increasing student awareness of the benefits of using adjectives to enhance their writing will likely go a long way in improving their ability to more effectively express themselves. In particular, students can benefit from explicit instruction into how to incorporate adjectives into their writing. Towards this end, Paraskevas's (2006) “Grammar Apprenticeship" approach can be adapted. In this approach, students can be guided to analyze the variety of ways adjectives are utilized in reflective writing papers composed by advanced users of English. This will help students better understand the choices authors make and develop "a feel for the beauty of [adjectives], for [their] power and strength and grace" (p. 65). They may be asked to reflect on how they currently use adjectives and how they may adopt and adapt the strategies other authors use. They are then asked to revise their reflective writing accordingly. With this increased understanding of the role of adjectives in expressive writing, they can make better informed decisions about how to express their engagement with critical thoughts, feelings, and attitudes. Overall, Paraskevas's approach supports the theory that the acquisition of effective writing is facilitated by learners' engagement in extensive reading of texts composed by competent authors (Krashen, 1984).

Paraphrasing in the form of editing can also be a useful activity. To this end, learners can be given a reflective writing piece with a limited number of qualitative adjectives. They can be asked to rephrase sentences using appropriate items from a list based on more sophisticated adjectives (e.g., the AWL). Considering the results of 
this study, female students, in particular, may benefit from having their attention drawn to adjectives in the AWL. Learners may also be given the freedom to use adjectives of their own choice, but they should be challenged to justify their choices. This could play an important role in engaging them towards greater reflection on language use in their reflective writing.

To raise their awareness of adjectives, learners can first be asked to identify all the qualitative adjectives in a well-drafted reflective writing essay and then to sort them out into categories according to meaning and usage. Their attention, in particular, can be drawn to attitudinal adjectives. To allow for interaction between students, groups/pairs of students may be asked to identify certain types of adjectives, after which an information exchange session is held.

The results of the current study regarding male and female students' use of adjectives are also important. While no significant differences were identified, it is important to develop a deeper understanding of how males and females approach the use of language generally and adjectives in particular in order to confirm or refute what others have found (Baker, 2014; Ishikawa, 2015; Lakoff, 1975; Tannen, 1990). One way to do this is to have students reflect on why they used particular adjectives in their writing. This can be done through brief reflections after they have completed a particular assignment. This would also serve as an ongoing reminder to students that it is important to remain cognizant of their use of adjectives as attitudinal stance markers.

\section{Conclusion}

In this paper, we attempted to describe how qualitative adjectives are used in reflective writing by first-year university students who are speakers of English as a foreign language. The nature of reflective writing requires authors to make references to their feelings, which necessitates the use of a significant number of adjectives. However, the students' use of adjectives in this study was relatively limited, pointing to the need for writing instructors to foster the development of students' reflective writing skills through purposefully designed pedagogical interventions.

We paid particular attention to the ways in which the male and the female students utilized adjectives in writing. The comparison between the data sets showed that the former had a greater tendency to use adjectives. However, the latter used adjectives as attitudinal markers more often. These findings point to gender differences in language use in reflective essays.

Considering the small scale of this study, the findings cannot be generalized to wider contexts. Further research is required for us to better understand the role adjectives play in students' pursuit of expressing themselves in reflective writing tasks. To this end, competent authors' writing habits can be investigated and compared to those of native and non-native students. This may reveal ways in which reflective writing instruction for EFL students can be better planned and implemented.

\section{Conflict of interests}

The authors declare that they have no conflict of interest.

\section{References}

Adams, K. (2013). Expressive writing: Foundations of practice. Rowman \& Littlefield Education.

Al Murshidi, G. (2014). Emirati and Saudi students' writing challenges at U.S. universities. English Language Teaching, 7(6), 87-95. https://doi.org/10.5539/elt.v7n6p87

Alkhrisheh, H., Aziez, F., \& Alkhrisheh, T. (2019). A study on gender and language differences in English and Arabic written texts. Research and Innovation in Language Learning, 2(2), 120-138. https://doi.org/10.33603/ rill.v2i2.2028

Ayish, N. (2020). Attitudes toward using English as a medium of instruction among Emirati male and female freshman engineering students. In E. Mede, K. Dikilitas \& D. Atay (Eds.), Pedagogic and instructional 
perspectives in language education: The context of higher education (pp. 195-223). Peter Lang Publishers. http:// dx.doi.org/10.3726/b16464

Baker, P. (2014). Using corpora to analyze gender. Bloomsbury

Barczewska, S., \& Andreasen, A. (2018). Good or marvelous? Pretty, cute or lovely? Male and female adjective use in MICASE. Suvremena Lingvistika, 44(86), 194-213. http://dx.doi.org/10.22210/suvlin.2018.089.02

Beaumont, S. L. (2019). The art of words: Expressive writing as reflective practice in art therapy. Canadian Art Therapy Association Journal, 31(2), 55-60. https://doi.org/10.1080/08322473.2018.1527610

Bernard, A.W., Gorgas, D., Greenberger, S., Jacques, A., \& Khandelwal, S. (2012). The use of reflection in emergency medicine education. Academic Emergency Medicine, 19(8), 978-982. https://doi.org/10.1111/ j.1553-2712.2012.01407.x

Biber, D., Johanson, S., Leech, G., Conrad, S., \& Finegan, E. (1999). Longman grammar of spoken and written English. Pearson.

Birney, R. (2012). Reflective writing: Quantitative assessment and identification of linguistic features [Unpublished doctoral dissertation]. Waterford Institute of Technology.

Boud, D., Keogh, R., \& Walker, D. (1985). Reflection: Turning experience into learning. Routledge, Abingdon, Oxon.

Boyd, E. M., \& Fales, A. W. (1983). Reflective learning: key to learning from experience. Journal of Humanistic Psychology, 23(2), 99-117. http://dx.doi.org/10.1177/0022167883232011

Brown, S. (2016). Effects of intrapersonal communication on reverse culture shock [Research Report]. http:// digitalcommons.calpoly.edu/cgi/viewcontent.cgi?article=1236\& context=comssp

Buckingham. L. (2008). Development of English academic writing competence by Turkish scholars. International Journal of Doctoral Studies, 3, 1-18. https://doi.org/10.28945/47

Burns, S., \& Bulman, C. (2000). Reflective practice in nursing. Blackwell Science.

Burton, C. M., \& King, L. A. (2004). The health benefits of writing about intensely positive experiences. Journal of Research in Personality, 38, 150-163. https://doi.org/10.1016/S0092-6566(03)00058-8

Çapar, M. (2014). Reflective writing in an EFL writing course. International Journal of Language Academy, 2(4), 470-486. https://doi.org/10.18033/ijla.118

Cisero, C. A. (2006). Does reflective journal writing improve course performance. College Teaching, 54(2), 231236. https://doi.org/10.3200/CTCH.54.2.231-236

Coates, J. (2016). Women, men and language ( $3^{\text {rd }}$ ed.). Routledge Linguistics Classics.

Coxhead, A. (2000). A new academic word list. TESOL Quarterly, 34(2), 213-238. https://doi.org/10.2307/3587951

Crowe, M.T., \& O'Malley, J. (2006). Teaching critical reflection skills for advanced mental health nursing practice: A deconstructive-reconstructive approach. Journal of Advanced Nursing, 56, 79-87. https://doi.org/10.1111/ j.1365-2648.2006.03982.x.

Deveci, T. (2015). Communication students' use of lexis in a writing examination. The Asian ESP Journal, 17(1), 39-63.

Deveci, T. (2017). Internet technology as an aid to traditional methods in the development of freshman students' use of academic words. Journal of Teaching English for Specific and Academic Purposes, 5(1), 55-76. https://doi. org/10.22190/JTESAP1701055D

Deveci, T., \& Nunn, R. (2018). Intrapersonal communication as a lifelong learning skill in engineering education. Journal of Higher Education, 8(1), 68-77. http://dx.doi.org/10.2399/yod.17.009

Dyment, J. E., \& O'Connell, T. S. (2011). Assessing the quality of reflection in student journals: A review of the research. Teaching in Higher Education, 16(1), 81-97. http://dx.doi.org/10.1080/13562517.2010.507308

Eckert, P. (1989). The whole woman: Sex and gender differences in variation. Language Variation and Change, 1(3), 245-268.

Eckstein, G., \& Ferris, D. (2018). Comparing L1 and L2 Texts and Writers in First-Year Composition. TESOL Quarterly, 52(1), 137-162. http://dx.doi.org/10.1002/tesq.376

Englander, K. (2014). Writing publishing science research papers in English: A global perspective. Springer.

Ferris, D. R. (2009). Teaching college writing to diverse student populations. University of Michigan Press. https:// doi.org/10.3998/mpub.263445

Forsell, S. (2011). Promotion the European Union: Attitudinal stance adjectives in three genres of EU communication to public [Unpublished Master's thesis]. University of Helsinki.

Gibson, A., Aitken, A., Sandor, A., Shum, S. B., Tsingos-Lucas, C., \& Knight, S. (2017). Reflective writing analytics for actionable feedback. Proceedings of the 7th International Conference on Learning Analytics and Knowledge (pp. 153-162). ACM. http://dx.doi.org/10.1145/3027385.3027436

Hagevik, R., Aydeniz, M., \& Glennon, R., C. (2012). Using action research in middle level teacher education to evaluate and deepen reflective practice. Teaching and Teacher Education, 28, 675-684. https://doi. org/10.1016/j.tate.2012.02.006 
Handler, C., Handler, C., \& Gill, D. (2011). English and reflective writing skills in medicine: A guide for medical students and doctors. Radcliffe.

Hardy, J. A., \& Friginal, E. (2016). Genre variation in student writing: A multi-dimensional analysis. Journal of English for Academic Purposes, 22, 119-131. http://dx.doi.org/10.1016/j.jeap.2016.03.002

Hatton N., \& Smith, D. (1995). Reflection in teacher education: Towards definition and implementation. Teaching \& Teacher Education, 11(1), 33-49. http://dx.doi.org/10.1016/0742- 051X(94)00012-U

Ishikawa, Y. (2011). A corpus-based research on thanks in British dialogue. International Proceedings of Economics Development \& Research, 26, 384-389.

Ishikawa, Y. (2015). Gender differences in vocabulary use in essay writing by university students. Procedia Social and Behavioral Sciences, 192, 593-600. http://dx.doi.org/10.1016/j.sbspro.2015.06.078

Jefferys, A. (2018, June 25). Language to use for writing a reflective essay. https://classroom.synonym.com/ language-use-writing-reflective-essay-3292.html

Kember, D., McKay, J., Sinclair, K., \& Wong, F. K. Y. (2008). A four-category scheme for coding and assessing the level of reflection in written work. Assessment \& Evaluation in Higher Education, 33(4), 369-379. http://dx.doi. org/10.1080/02602930701293355

Kilgore, D., Sattler, B., \& Turns, J. (2013). From fragmentation to continuity: Engineering students' narratives about the benefits of developing a professional portfolio. Studies in Higher Education, 38(6), 807-826. https:// doi.org/10.1080/03075079.2011.610501

King, L.A. (2001). The health benefits of writing about life goals. Personality and Social Psychology Bulletin, 27, 298-807. https://doi.org/10.1177\%2F0146167201277003

Klenowski, V. (2002). Developing portfolios for learning and assessment: Processes and principles. RoutledgeFalmer.

Krashen, S. (1984). Writing: Research, theory and application. Pergamon Institute of English. https://doi. org/10.1017/s0272263100006197

Lakoff, R. (1975). Language and woman's place. Harper and Row.

Lee, B., Fitria, A., \& Ginting, H. (2019). Analysing literacy and other psychological tendencies using linguistic profile in English expressive writing: Are students able but unwilling to write? Indonesian Journal of Applied Linguistics, 9(1), 27-37. https://doi.org/10.17509/ijal.v9i1.12698

Lew, M. D. N. \& Schmidt, H. G. (2011). Self-reflection and academic performance: Is there a relationship? Advances in Health Sciences Education, 16(4), 529-545. https://doi.org/10.1007/s10459-011-9298-z

$\mathrm{Lu}, \mathrm{X}$., \& Ai, H. (2015). Syntactic complexity in college-level English writing: Differences among writers with diverse L1 backgrounds. Journal of Second Language Writing, 29, 16-27. http://dx.doi.org/10.1016/j.jslw.2015.06.003

Lyubormirsky, S. Sousa, L., \& Dickerhoof, R. (2006). The cost and benefits of writing, thinking about life's triumphs and defeats. Journal of Personality and Social Psychology, 90(4), 692-708.

MacLellan, E. (2004). How reflective is the academic essay? Studies in Higher Education, 29(1), 75-89. http:// dx.doi.org/10.1080/1234567032000164886

Magno, C. (2009). Self-regulation and approaches to learning in English composition writing. TESOL Journal, 1(1), 1-16.

Mann, K., Gordon, J., \& MacLeod, A. (2007). Reflection and reflective practice in health professions education: A systematic review. Advances in Health Sciences Education, 14, 595-621. https://doi.org/10.1007/s10459-007-9090-2

Mason, C. P. (1858). English grammar: Including the principles of grammatical analysis. Walton \& Maberly.

Mauk, J., \& Metx, J. (2013). Inventing arguments. Wadsworth.

Mezirow, J. (1998). On critical reflection. Adult Education Quarterly, 48(3), 185-198.

Moon, J. (2004). A handbook of reflective and experiential learning: Theory and practice. Routledge Falmer.

Moon, J. (2006). Learning journals: A handbook for reflective practice and professional development. Routledge.

Moussa-Inaty, J. (2015). Reflective writing through the use of guiding questions. International Journal of Teaching and Learning in Higher Education, 27(1), 104-113.

Murray, K. (2014). Adjectives and adverbs. PowerKiDS Press.

Newman, M. L., Groom, C. J., Handelman, L. D., \& Pennebaker, J. W. (2008). Gender differences in language use: An analysis of 14,000 text samples. Discourse Processes, 45(3), 211-236. https://doi. org/10.1080/01638530802073712

Nguyen, Q.D., Fernandez, N., Karsenti, T., \& Charlin, B. (2014). What is reflection? A conceptual analysis of major definitions and a proposal of a five-component model. Medical Education, 48, 1176-1189. https://doi. org/10.1111/medu.12583

Nunn, R., \& Brandt, C. (2016). A phenomenological approach to teaching reflective writing. English Scholarship Beyond Borders, 2(1), 130-142.

Paraskevas, C. (2006). Apprenticeship. The English Journal, 95(5), 65-70. https://doi.org/10.2307/30046591 
Plack, M. M., Driscoll, M., Blissett, S., McKenna, R., \& Plack, T. P. (2005). A method for assessing reflective journal writing. Journal of Allied Health, 34(4), 199-205.

Rayson, P., Berridge, D., \& Francis, B. (2004). Extending the Cochran rule for the comparison of word frequencies between corpora. In G. Purnelle, C. Fairon, \& A. Dister (Eds.). Le poids des mots: Proceedings of the $7^{\text {th }}$ International Conference on Statistical analysis of textual data (JADT 2004) (pp. 926-936). Louvain-la-Neuve.

Reidsema, C. (2009). Assessing reflective writing: Analysis of reflective writing in an engineering design course. Journal of Academic Language \& Learning, 3(3), 117-129.

Rodgers, C. (2002). Defining reflection: Another look at John Dewey and reflective thinking. Teachers College Record, 104(4), 842-866. https://doi.org/10.1111/1467-9620.00181

Rubin, D. L., \& Greene, J. (1992). Gender-typical style in written language. Research in the Teaching of English, 26(1), 7-40.

Rusche, S., \& Jason, K. (2011). You have to absorb yourself in it: Using inquiry and reflection to promote student learning and self-knowledge. Teaching Sociology, 39, 338-353. https://doi.org/10.1177\%2F0092055X11418685

Russell, T. (2005). Can reflective practice be taught? Reflective Practice, 6(2), 199-204. https://doi. org/10.1080/14623940500105833

Ryan, M. (2011). Improving reflective writing in higher education: A social semiotic perspective. Teaching in Higher Education, 16(1), 99-111. http://dx.doi.org/10.1080/13562517.2010.507311

Schön, D.A. (1987). Educating the reflective practitioner: Toward a new design for teaching and learning in the professions. Jossey-Bass.

Stillar, G. F. (1988). Analyzing everyday texts: Discourse, rhetoric, and social perspectives. SAGE.

Sumsion, J. \& Fleet, A. (1996). Reflection: Can we assess it? Should we assess it? Assessment \& Evaluation in Higher Education, 21(2), 121-130. http://dx.doi.org/10.1080/0260293960210202

Tannen, D. (1990). You just don't understand: Women and men in conversation. Ballantine Books.

Thabet, R. (2008). Do public schools in UAE foster critical thinking as one of the main objectives of education? xUnpublished Master's thesisъ. British University in Dubai.

Turns, J., Newstetter, W., Allen, J. K., \& Mistree, F. (1997). Learning essays and the reflective learner: Supporting reflection in engineering design education. In Proceedings of the ASEE Annual Conference (pp. 2.274.1 2.274.14). Milwaukee, WI. https://doi.org/10.18260/1-2--6665

Tsingos-Lucas, C., Bosnic-Anticevich, S., Schneider, C.R., \& Smith, L. (2017).Using reflective writing as a predictor of academic success in different assessment formats. American Journal of Pharmaceutical Education, 81(1), Article 8. https://doi.org/10.5688/ajpe8118

Ullmann, T. D. (2019). Automated Analysis of reflection in writing: Validating machine learning approaches. International Journal of Artificial Intelligence in Education, 29, 217-257. https://doi.org/10.1007/ s40593-019-00174-2

van Weijen, D. (2014, September 29). How to overcome common obstacles to publishing in English. https://www. elsevier.com/authors-update/story/publishing-tips/how-to-overcome-common-obstacles-to-publishingin-english

Wallin, P., \& Adawi, T. (2018). The reflective diary as a method for the formative assessment of self-regulated learning. European Journal of Engineering Education, 43(2), 507-521. https://doi.org/10.1080/03043797.2017 .1290585

Wenjing, X. (2012). Study on gender differences in English. International Conference on Education Technology and Management Engineering, (16-17), 218-221.

West, M. (1953). A general service list of English words. Longman.

Wong, F. K. Y., Kember, D., Chung, L. Y.F., \& Yan, L. (1995). Assessing the level of student reflection from reflective journals. Journal of Advanced Nursing, 22(1), 48-57. http://dx.doi.org/10.1046/j.1365-2648.1995.22010048.x

Zulfikar, T., \& Mujiburrahman, A. (2018). Understanding own teaching: Becoming reflective teachers through reflective journals. Reflective Practice, 19(1), 1-13. https://doi.org/10.1080/14623943.2017.1295933 